\title{
Nodal CD8 Positive Cytotoxic T-Cell Lymphoma: A Distinct Clinicopathological Entity
}

Harumi Y. Mukai, M.D., Yuichi Hasegawa, M.D., Hiroshi Kojima, M.D., Yasushi Okoshi, M.D., Naoko Takei, M.D., Yoriko Yamashita, M.D., Toshiro Nagasawa, M.D., Naoyoshi Mori, M.D.

Division of Hematology (HYM, YH, HK, YO, NT, TN), Institute of Clinical Medicine, University of Tsukuba, Tsukuba, Japan; and First Department of Pathology (YY, NM), Nagoya University School of Medicine,

Showa-ku, Nagoya, Japan

We studied 11 cases of nodal cytotoxic T-cell lymphoma, which express the CD8+ phenotype and cytotoxic molecules (T-cell intracellular antigen-1, granzyme $B$ and perforin), to characterize the clinicopathologic spectrum of these neoplasms. The 11 cases consisted of four men and seven women, aged 5 to 82 years (mean, 53 years). All cases were nodal, and eight of 11 had extranodal involvement, the most common being in bone marrow (eight cases) and liver (six cases). The expression of these cytotoxic molecules has been reported in some T/natural killer cell lymphomas mostly involved in extranodal sites of skin, nasopharyngeal region, or gastrointestinal tracts, but these types of extranodal involvement were rare in our cases. Morphologically these lymphomas could be divided into two groups. One group $(n=6)$ showed a diffuse large cell type and massive necrosis or apoptosis that was accompanied by disseminated intravascular coagulation (DIC) or hemophagocytic syndrome (HPS) on the initial. The prognosis of this group was generally poor (survival $=1-19$ months, median $=5 \mathrm{mo}$ ), and four of these six cases were fulminant. The other group $(n=5)$ showed a diffuse medium or mixed cell type, and the prognosis was not so poor (median survival $=17 \mathrm{mo}$ ). Our results suggest that these nodal cytotoxic T-cell lymphomas originated from activated cytotoxic T-cells and were highly accompanied with DIC or HPS.

KEY WORDS: CD8, Cytotoxic T-cell, DIC, HPS. Mod Pathol 2002;15(11):1131-1139

Copyright $\odot 2002$ by The United States and Canadian Academy of Pathology, Inc.

VOL. 15, NO. 11, P. 1131, 2002 Printed in the U.S.A.

Date of acceptance: August 7, 2002.

Address reprint requests to: Harumi Y. Mukai, M.D., Ph.D., Division of Hematology, Institute of Clinical Medicine, University of Tsukuba,

Tsukuba, Ibaraki, 305-8575, Japan; e-mail: hmukai@md.tsukuba.ac.jp; fax: 81-298-53-3127.

DOI: 10.1097/01.MP.0000036343.61268.64
Cytotoxic cell-associated molecules, T-cell intracellular antigen-1 (TIA-1), granzymes, and perforin, are primarily expressed on natural killer (NK) cells or cytotoxic T-cells (1-4). The expression of these molecules has been reported in T- or NK cell neoplasms $(5,6)$, large granular lymphocytic leukemia (7, 8), NK-cell leukemia/lymphoma (9-13), hepatosplenic $\gamma \delta$ T-cell lymphoma $(14,15)$, subcutaneous panniculitic T-cell lymphoma $(16,17)$, enteropathytype intestinal T-cell lymphoma $(5,14)$, and anaplastic large cell lymphoma (ALCL) $(18,19)$. Each of these leukemia/lymphomas except for ALCL occurred in extranodal sites, such as liver, skin, nasopharyngeal region, and gastrointestinal tract.

Cytotoxic T- or NK cells play a defensive role against neoplasms and viral infections $(20,21)$. Cytotoxic cells induce lysis of target cells with two mechanisms: granule exocytosis and the Fas-Fas ligand pathway (20-23). Cytotoxic cell-associated molecules, TIA-1, granzymes, and perforin, play roles in the former mechanism $(1,4,22,24)$. Perforin forms pores on the target cell membrane and induces necrosis similar to that induced by complement C9 (3, 4). TIA-1 (24) and granzymes (22) move to the cytoplasm through the perforinformed pore and activate apoptosis-associated proteins $(25,26)$. Although perforin and granzymes are expressed in cytotoxic cells only when these cells are activated (27) and are associated with the induction of cytolytic activity (28-30), TIA-1 is expressed in cytotoxic cells, regardless of their activation status, and in myeloid cells $(1,24,31)$.

Cytotoxic lymphocytes include three cell types: CD8+ cytotoxic T-cells, NK cells, and CD4+ cytotoxic T-cells $(27,32)$. Most peripheral T-cell lymphomas (PTCLs) previously reported have a CD4+ phenotype, frequently involve extranodal sites, and rarely have a CD8+ phenotype (33). In this study, we examined the histopathological and clinical features of 11 cases of nodal CD8 + PTCLs that strongly express cytotoxic molecules. 


\section{MATERIALS AND METHODS}

\section{Patients}

We studied 155 T-cell lymphoid malignancy patients at the Division of Hematology, University of Tsukuba, and the First Department of Pathology, Nagoya University School of Medicine, during the period 1993-2000.

\section{Paraffin Tissues}

Lymph node samples were fixed in a $10 \%$ formaldehyde solution and embedded in paraffin. Sections were cut 2 to $4 \mu \mathrm{m}$ thick and were stained with hematoxylin and eosin. An avidin-biotinperoxidase complex (Nichirei, Tokyo, Japan) method was used along with the following antibodies: polyclonal CD3, CD8 and CD30 (BerH2) (DAKO, Copenhagen, Denmark); CD4 (Novocastra Laboratories, Newcastle, England); CD43 (Bioscience Products, Emmerbruecke, Switzerland); CD15 (LeuM1, Becton-Dickinson, San Jose, CA, USA); CD45RO (UCHL-1; Nichirei, Tokyo, Japan); TIA-1 (Coulter, Miami, FL, USA) granzyme B (Monozan, Ueden, Netherlands); and $\beta \mathrm{F} 1$ (T-cell Sciences, Cambridge, MA). For the $\beta$ Flantibody, proteinase K (Sigma, St. Louis, MO), digestion was used for antigen retrieval.

\section{Frozen Tissue}

Fresh tissue specimens were fixed in a periodatelysine-paraformaldehyde fixative, frozen, and cut with a cryostat to a thickness of 6 to $8 \mu \mathrm{m}$. Sections were then fixed with acetone for 10 minutes and stained by the avidin-biotin-peroxidase complex method with the following primary antibodies: anti-Leu1 (CD5), Leu2 (CD8), Leu3 (CD4), Leu4 (CD3), Leu9 (CD7), and Leu19 (CD56) (Becton Dickinson, San Jose, CA); anti- $\beta$ F1, TCR $\delta 1$, and perforin (T-cell Diagnostics, Cambridge, MA).
In Situ Hybridization (ISH) Analysis

After deparaffinization and digestion with proteinase $K$, the tissue sections were hybridized with fluorescein-conjugated oligonucleotide probes for Epstein-Barr virus (EBV) encoded RNA (EBER) (EBV probe ISH kit, Novocastra). Stringently washed sections were reacted with anti-fluorescein antibody and visualized with 5-bromo-4-chloroindolylphosphatase and nitroblue tetrazolium salt. Details of this ISH procedure are described elsewhere (34).

\section{ELISA of IFN- $\gamma$ and TNF- $\alpha$}

Serum levels of cytokines, IFN- $\gamma$ and TNF- $\alpha$, were measured by an enzyme-linked immunosorbent assay (ELISA) using ELISA tests (Bender Medsystems, Vienna, Austria). Details of the assays are described elsewhere (35).

\section{RESULTS}

\section{Clinical Features}

Among the $155 \mathrm{~T}$-cell lymphomas that we examined, we found 11 cases of nodal CD8+ PTCLs that strongly express cytotoxic molecules. We examined the clinical and histopathological features of these 11 cases. These cases consisted of four male and seven female patients ranging in age from 5 to 82 years (median age, 53 years). Table 1 shows the clinical and morphological findings of these lymphoma patients. All 11 cases had nodal involvement. Eight patients had extranodal involvement (bone marrow, eight patients; liver, six; skin, two; lung, two; central nervous system (CNS), two; gastrointestinal tracts, one). The 11 nodal cytotoxic lymphomas were divided into two groups based on their cell morphology. One group is a large cell type and the other group is a medium or mixed cell type. In the large cell type group, five of six patients (Cases 2, 3, 4, 5, and 6) had hemophagocytic syndrome (HPS) and four of these cases had dissemi-

TABLE 1. Morphological and Clinical Features of Nodal Cytotoxic T-Cell Lymphomas

\begin{tabular}{|c|c|c|c|c|c|c|}
\hline Case & Age/Sex & Subtype & Involved Sites & Stage & DIC/HPS & Apoptosis/Necrosis \\
\hline 1 & $82 / \mathrm{F}$ & DL & LN, SP & IIIA & & +++ \\
\hline 2 & $77 / \mathrm{M}$ & DL & LN, LV, SP & IIIB & $+1+$ & +++ \\
\hline 3 & $75 / \mathrm{F}$ & DL & LN,BM, LV,SP, CNS & IVB & $+1+$ & - \\
\hline 4 & $22 / \mathrm{M}$ & DL & LN,BM, LV,SP, GI,CNS,SK,LG & IVB & $-1+$ & - \\
\hline 5 & $35 / F$ & DL & LN,BM,CNS & IVB & $+1+$ & ++ \\
\hline 6 & $5 / \mathrm{F}$ & DL & LN,BM, LV, SP & IVB & $+1+$ & + \\
\hline 7 & $33 / \mathrm{M}$ & Dmix & LN,BM, LV, SP & IVB & $+1-$ & ++ \\
\hline 8 & $72 / \mathrm{F}$ & Dmix & LN,BM, LV,SP,tonsil & IVG & $-1-$ & - \\
\hline 9 & $76 / \mathrm{F}$ & Dmix & LN,BM, SK, LG & IVB & $+1+$ & - \\
\hline 10 & $30 / \mathrm{F}$ & Dmed & $\mathrm{LN}, \mathrm{BM}$ & IVA & $-1-$ & - \\
\hline 11 & $72 / \mathrm{M}$ & Dmed & LN, WR & IIA & $-1-$ & - \\
\hline
\end{tabular}

F, female; M, male; DL, diffuse large; Dmix, diffuse mixed; Dmed, diffuse medium; LN, lymph node; BM, bone marrow; LV, liver; SP, spleen; CNS, central nerve system; GI, gastrointestinal tracts; SK, skin; LG, lung; WR, Waldeyer's ring; DIC, disseminated intravascular coagulation; HPS, hemophagocytic syndrome. 
nated intravascular coagulation (DIC) in their initial courses. Table 2 shows the treatment and outcome of these patients. The clinical course of four patients (Cases 1, 2, 6, and 7) was fulminant because of their DIC, HPS, or HUS. Because the performance status of these four patients was severe, they could not be given conventional chemotherapy. Patient 4 achieved a complete remission (CR) with intensive chemotherapy, but he died of sepsis in the neutropenic period after high-dose chemotherapy and auto-peripheral blood stem cell transplantation. Patient 5 was refractory to the conventional chemotherapy, and she also died of sepsis in the neutropenic period after intensive chemotherapy. Compared with the large cell type group, lymphomas of the medium or mixed cell type group were sensitive to conventional chemotherapy, and overall survival (17 mo) was longer. DIC and HPS were observed when their lymphomas showed relapse or regrowth (Cases 8, 9, 11) (Fig. 1).

\section{Morphological Findings}

All 11 cases were categorized "PTCL, unspecified" according to the REAL classification. Six cases were diagnosed as diffuse, large cell type, three as diffuse, mixed cell type and two as diffuse, mediumsized cell type with provisional entity. Of the six cases diagnosed as diffuse, large cell type, four cases were accompanied by massive necrosis or apoptosis and in two of four cases the neoplastic cells were scattered in the phagocytizing macrophages or necrotic tissue (Fig. 2, A-B). The neoplastic cells of diffuse, large cell type occasionally had a round or ovoid nucleus but most of them had nuclear irregularities, with marked convolution or with a slender, elongated nuclear shape. The nuclear chromatin in the neoplastic cells was densely stained. The nucleolus was not conspicuous.

The proliferating cells of the diffuse, mediumsized type consisted of round medium sized cells

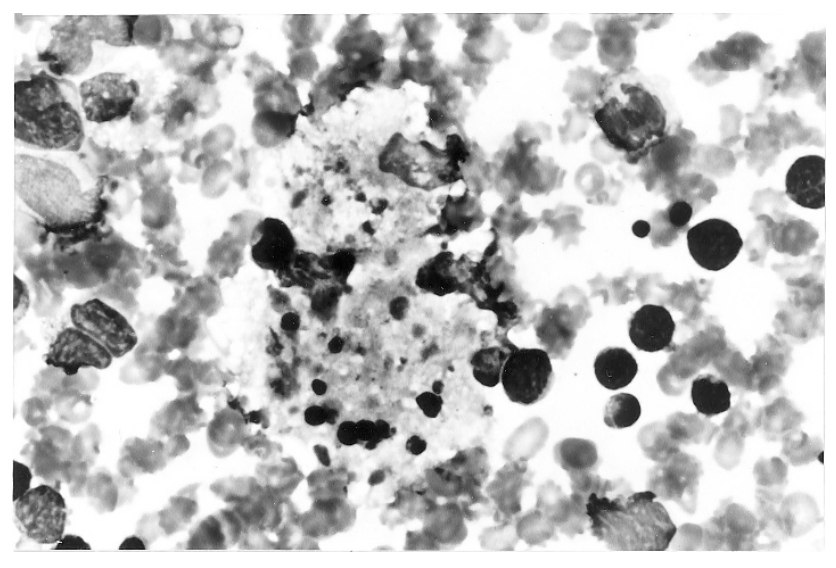

FIGURE 1. Bone marrow smear specimen shows hemophagocytosis of macrophages ingesting nuclear fragments of the cells (Case 11; medium sized cell type) (original magnification, $680 \times$ ).

with small cleaved-like nuclei. The neoplastic cells had densely stained nuclear chromatin (Fig. 3 ). These small cleaved-like cells were characteristic in our nodal cytotoxic T-cell lymphomas. In lymphomas of the diffuse, large cell type, large cells with a round or ovoid nucleus were predominant, but there were scattered proliferations of small cleaved-like cells (Fig. 2C). Although necrosis and apoptosis were often conspicuous in lymphomas of the diffuse, large cell type, these were not prominent in lymphomas of diffuse, mediumsized cell type. The neoplastic cells of the diffuse, mixed cell type consisted of both large and medium-sized cells (Fig. 4). In one case of the diffuse, mixed cell type, widespread necrosis and apoptosis were observed.

\section{Immunohistochemical Findings and EB-Virus ISH}

Table 3 summarizes the immunohistochemical findings of these cases. All of the CD8+ PTCLs were positive for CD3 and CD8, but other pan-T

TABLE 2. Treatment and Clinical Course of Nodal Cytotoxic T-Cell Lymphomas

\begin{tabular}{|c|c|c|c|}
\hline Case & Treatment & Cause of Death & Clinical Course \\
\hline 1 & Low dose COP, Rad 9 Gy & Bleeding & 2 mo (DOD) \\
\hline 2 & $\mathrm{VP}$ & DIC, HPS & $1 \mathrm{mo}$ (DOD) \\
\hline 3 & $\mathrm{CHOP} \rightarrow \mathrm{PR} \rightarrow$ regrowth $\rightarrow \mathrm{COP}, \mathrm{EPOCH}$ & Sepsis & 19 mo (DOD) \\
\hline 4 & Ara- $\mathrm{C}+\mathrm{CHOP} \rightarrow \mathrm{CR} \rightarrow$ auto-PBSCT & Sepsis & 5 mo (DOD) \\
\hline 5 & $\mathrm{CHOP} \rightarrow \mathrm{PD} \rightarrow l$-Asp $+\mathrm{VP} \rightarrow$ Ara-C $+\mathrm{MIT}$ & Sepsis & 2 mo (DOD) \\
\hline 6 & Steroid & DIC, HPS & 20 days (DOD) \\
\hline 7 & Plasma exchange & HUS & 10 days (DOD) \\
\hline 8 & $\mathrm{CHOP} \rightarrow \mathrm{CR} \rightarrow$ relapse $\rightarrow$ ESHAP & & 19 mo (AD) \\
\hline 9 & $\mathrm{CHOP} \rightarrow \mathrm{CR} \rightarrow$ relapse $\rightarrow \mathrm{CHOP}-\mathrm{E}$ & DIC, HPS & 16 mo (DOD) \\
\hline 10 & $\mathrm{CHOP} \rightarrow \mathrm{PR} \rightarrow \mathrm{DeVic}$ & Pneumonia & 21 mo (DOD) \\
\hline 11 & $\mathrm{CHOP} \rightarrow \mathrm{PR} \rightarrow \mathrm{ESHAP} \rightarrow$ Rad 50 Gy & DIC, HPS & 27 mo (DOD) \\
\hline
\end{tabular}

COP, cyclophosphamide (CPA) + vincristin (VCR) + prednisolone (PRD); VP, VCR + PRD; CHOP, CPA + doxorubicin (DXR) + VCR + PRD; EPOCH, etoposide (VP-16) + CPA + DXR + VCR + PRD; Ara-C, cytocine arabinoside, $l$-ASP, asparaginase; MIT, mitoxantrone; ESHAP, VP-16 + methylprednisolone + Ara-C + Cisplatin (CDDP); CHOP-E, CHOP + VP-16; DeVic, dexamethasone + VP-16 + ifosfamide (IFO) + carboplatin (CBDCA); PBSCT, peripheral blood cell transplantation; PR, partial response; CR, complete response; PD, progressive disease; HUS, hemolytic uremic syndrome; DOD, dead of disease; $\mathrm{AD}$, alive with disease. 


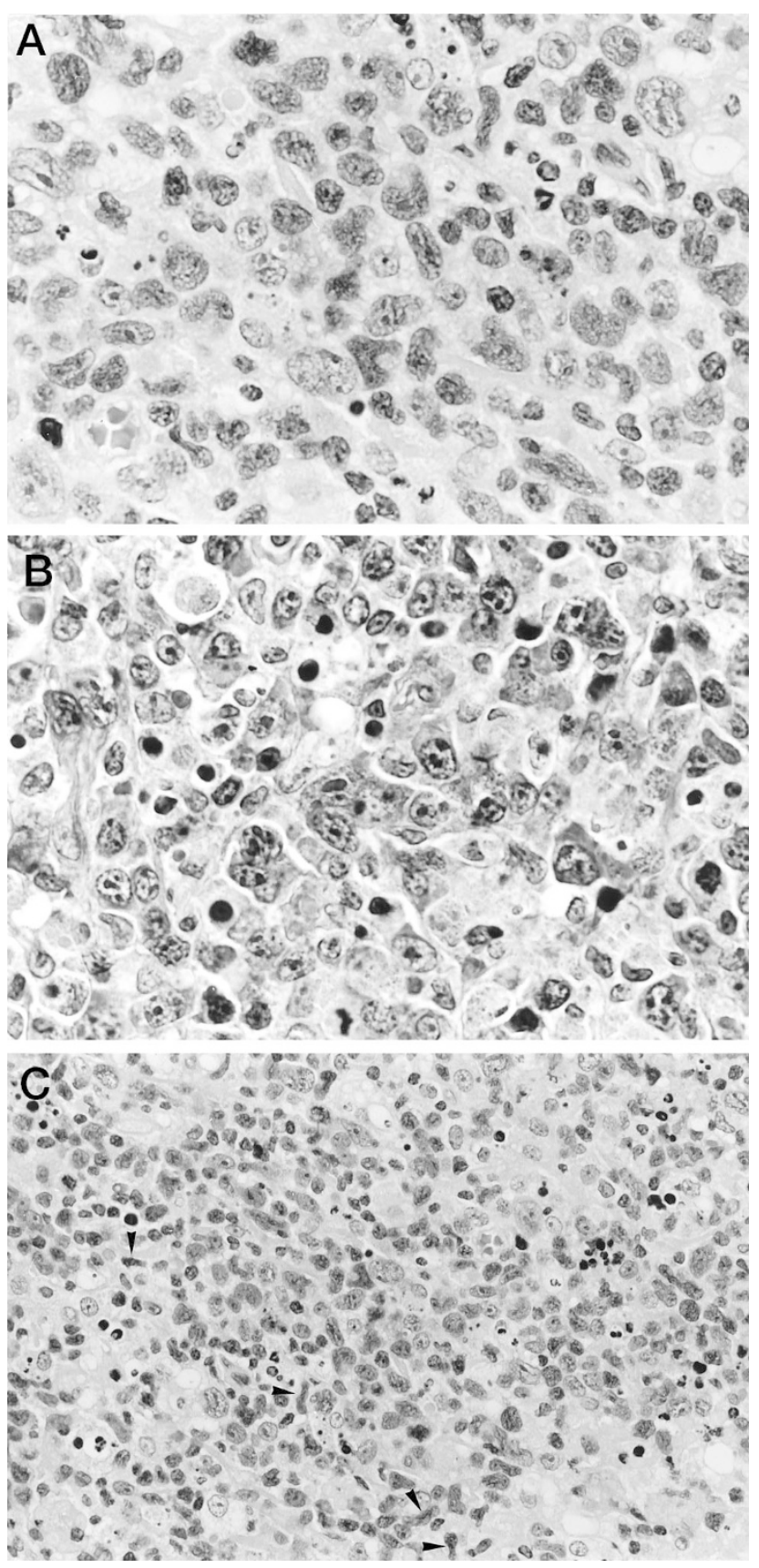

FIGURE 2. A, B, C, HE staining of cases with diffuse, large cell type. Lymph node biopsy showed large neoplastic cells having irregular shaped or elongated nucleus admixed with a large number of macrophages containing necrotic substance (A, Case 1; B, Case 2) (original magnification, $680 \times$ ). These atypical cells have relatively dense nuclear chromatin and indistinct nucleolus. Arrowheads show small cleaved-like cells in diffuse, large cell type (C, Case 1) (original magnification, $340 \times$ ).

antigens, such as CD5 and CD7 were lost in some cases (Figs. 5 and 6). Expression of CD56 was not seen in any case. CD15 and CD30 were also negative in all cases. Cytotoxic molecular markers, TIA-1, granzyme B (GrB) and perforin, were positively detected in all cases (Figs. 7-9). EB virus was detected in the neoplastic cells of five cases (Case 2, 6, 9, 10 and 11) (Fig. 10).

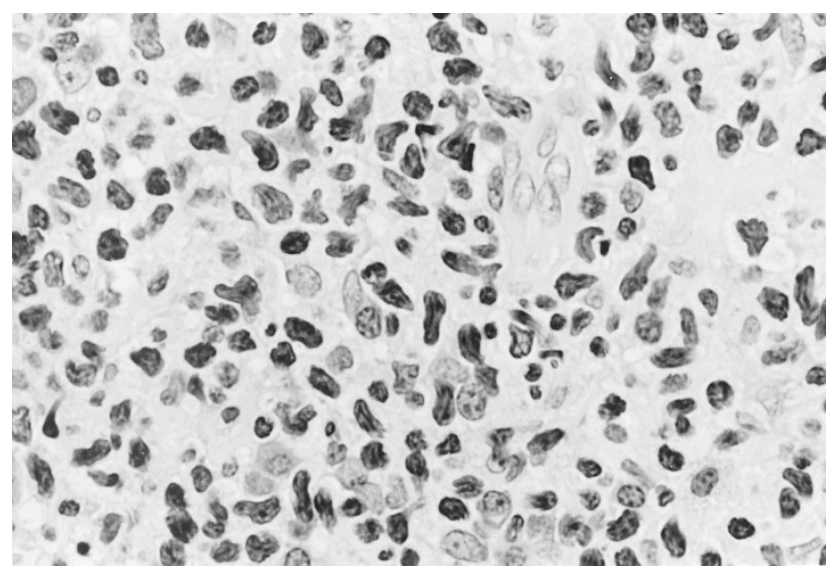

FIGURE 3. HE staining of a case with diffuse, medium-sized cell type. The tonsil showed a large number of small cleaved-like cells (medium-sized neoplastic cells with irregular or slender shaped nucleus) (Case 11) (original magnification, $680 \times$ ).

\section{Serum levels of Cytokines}

Serum levels of IFN- $\gamma$ and TNF- $\alpha$ were measured using the ELISA method in the clinical courses of Cases 9 and 11. In Case 9, a 76-year-old woman, the level of IFN- $\gamma$ was $0.9 \mathrm{IU} / \mathrm{mL}$ when lymphadenopathy was first revealed but lymphoma was not diagnosed based on her cervical lymph node biopsy. Ten months later, the IFN- $\gamma$ level became very high $(126 \mathrm{IU} / \mathrm{mL})$ with the diagnosis of cytotoxic T-cell lymphoma and DIC, whereas the level of TNF- $\alpha$ was within normal limits. In Case 11, a 72-year-old man, the level of IFN- $\gamma$ was normal in his initial disease, but increased to high level (107 IU/mL) with a recurrence of his lymphoma and HPS, whereas the level of TNF- $\alpha$ was low $(10 \mathrm{pg} / \mathrm{mL})$ although HPS was present.

\section{DISCUSSION}

We present here 11 nodal cytotoxic T-cell lymphomas having the $\mathrm{CD} 3+, \mathrm{CD} 4-$, $\mathrm{CD} 8+$ phenotype and that highly expressed cytotoxic molecules perforin, GrB and TIA-1. Clinically these cytotoxic lymphomas were often accompanied with DIC and HPS, and the prognosis was poor, and occasionally fulminant. All of these lymphomas involved lymph nodes, and in eight of the 11 cases there was extranodal involvement with bone marrow, liver and CNS. Most T-cell lymphomas and NK cell lymphomas involve extranodal sites (36) of the skin, nasopharyngeal region and GI tract, but the involvement of theses sites was rare in the present 11 cases.

Morphologically, our nodal cytotoxic T-cell lymphoma were characterized by small cleaved-like cells (medium sized cells). These cells were also characteristic in the cases of nasal NK cell lymphoma $(12,37)$. According to Chan et al., such cells 


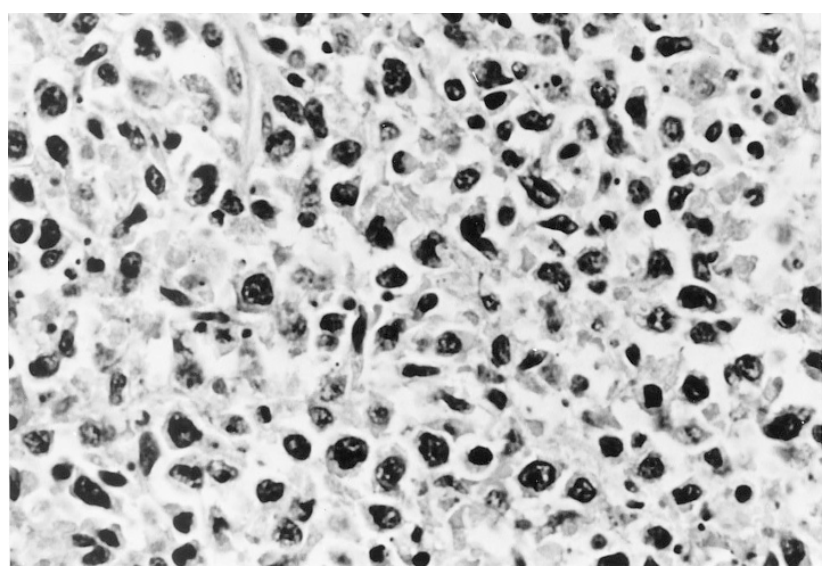

FIGURE 4. HE staining of a case with diffuse, mixed cell type. The liver (autopsy) showed large cells and small cleaved-like cells (Case 7) (original magnification, $680 \times$ ).

have elongated nuclei similar to small cleaved cells of B-cell lymphoma. But the small cleaved-like cells have dense chromatin in their nuclei and this finding can differentiate them from B-cell type small cleaved cells (37).

Cytotoxic lymphocytes consist of CD8+ cytotoxic T-cells, CD4 + cytotoxic T-cells and NK cells (27, 32, 38 ). These cytotoxic lymphocytes recognize and kill target cells with two different mechanisms. Fas-Fas ligand is thought to be the major pathway of CD4+ cytotoxic T-cells (23). Perforin and effector molecules of granzymes and TIA-1 participate in the other mechanism used by CD8+ cytotoxic T-cells and NK cells $(1,4,21,22,24)$. The expression of perforin and GrB is also observed in CD4+ cytotoxic T-cells (27), but is rare in CD4+ PTCLs. Yamashita et al. showed that only one of 63 cases of CD4+ PTCLs was histochemically positive for GrB (33). In our study of 155 cases with T-cell lymphomas, there were seven cases expressing cytotoxic molecules but not CD8+. Of these seven cases, only one (a case of $\mathrm{CD} 4+$ Lennert's lymphoma) expressed the full range of cytotoxic molecules (TIA-1, $\mathrm{GrB}$, and perforin). Of the other six of these seven cases, four cases of nodal CD4+ PTCLs and two cases of CD4+ cutaneous T-cell lymphomas expressed TIA-1 but not GrB and perforin.

Perforin forms pores on the target cell membranes, and effector molecules such as granzymes and TIA-1, enter the cytoplasm through the pore and then activate caspases, which results in cell apoptosis $(1,4,21,22,24)$. GrB is a serine protease and does not have cytolytic activity by itself, although DNA damage is observed when it is combined with a sublytic concentration of perforin. GrB is seen in activated cytotoxic T-cells or NK cells (28, 29), whereas TIA-1 is expressed in either resting or activated cytotoxic T-cells, NK cells and myeloid cells such as granulocytes $(1,24,31)$. Expression of these cytotoxic molecules has been studied in many types of malignant lymphomas (5-19). Such molecules are most frequently detected in extranodal T/NK cell lymphomas (5).

Recently several studies have demonstrated the expression of TIA- 1 and/or GrB in ALCLs. Kagami et al. studied 66 patients with cytotoxic molecules expressing nodal lymphomas (39). They showed most of p80-positive ALCLs expressed TIA-1 but the rate of positivity for GrB was lower, whereas seven of large T-cell lymphomas were all positive for TIA-1 and GrB. Another study also showed that the expression of GrB was lower in ALCLs (40). Yamashita et al. showed that Lennert's lymphoma was a variant of cytotoxic T-cell lymphoma because of the expression of TIA-1, but the expression of GrB was low, and the reason was probably because some cases of Lennert's lymphoma were derived from immature or inactive cytotoxic T-cells similar to ALCL or hepatosplenic $\gamma \delta$ lymphoma (41). Boulland et al. found that TIA-1 was expressed in all the lymphomas studied such as NK cell lymphoma, hepatosplenic $\gamma \delta$ lymphomas and PTCLs, regardless of the activation status of these lymphoma cells (39). On the other hand, the expressions of perforin and granzymes were greatly increased in activated cytotoxic lymphomas, NK-cell lymphomas, nonhepatosplenic $\gamma \delta$ lymphomas and subcutaneous panniculitic T-cell lymphomas (42). Although Boulland et al. showed that perforin and granzymes were expressed in only 33\% of the cases of $\alpha \beta$ PTCLs, they were expressed in four out of five (80\%) cases having the CD4-, CD8+ phenotype. The data in Table 4 show that the expressions of perforin and GrB were less positive in ALCL, hepatosplenic $\gamma \delta$ T-cell lymphoma and Lennert's lymphoma compared with CD8+ PTCLs, NK-cell lymphoma, nonhepatosplenic $\gamma \delta$ lymphoma, subcutaneous panniculitic T-cell lymphomas and our cases, whereas TIA-1 was highly expressed in almost all these lymphomas. In our study of $155 \mathrm{~T}$-cell lymphomas, there were five cases of subcutaneous panniculitic T-cell lymphoma and two cases of enteropathytype intestinal T-cell lymphoma. And all these seven cases revealed the phenotype, CD8+ and the full range of cytotoxic molecules, such as nodal cytotoxic T-cell lymphomas. Subcutaneous panniculitic T-cell lymphoma is characterized by primary involvement of subcutaneous fat and is frequently accompanied with hemophagocytic syndrome. Kumar et al. showed that most (13 out of 16) subcutaneous panniculitic T-cell lymphomas were $\mathrm{CD} 8+$, and that all 16 cases were positive for TIA-1 and perforin. And apoptosis was frequently observed and may be mediated by release of cytotoxic granule proteins (42).

In contrast to subcutaneous panniculitic $\mathrm{T}$-cell lymphoma and intestinal T-cell lymphoma, half 


\begin{tabular}{|c|c|c|c|c|c|c|c|c|c|c|c|c|c|c|c|}
\hline Case & CD3 & CD4 & CD5 & CD7 & CD8 & CD15 & CD30 & CD43 & CD45Ro & CD56 & $\beta \mathrm{F} 1$ & EBER-1 & TIA-1 & GrB & $\mathrm{Pf}$ \\
\hline 1 & + & - & - & + & + & - & - & + & + & - & - & - & + & + & + \\
\hline 2 & + & - & + & + & + & - & - & + & + & - & + & + & + & + & + \\
\hline 3 & + & - & + & - & + & - & - & + & + & - & + & - & + & + & + \\
\hline 4 & + & - & + & + & + & - & - & + & + & - & + & - & + & + & + \\
\hline 5 & + & - & $+1-$ & + & + & - & - & + & + & - & + & - & + & + & + \\
\hline 6 & + & - & $\mathrm{ND}$ & ND & + & - & - & $+1-$ & + & - & + & + & + & + & + \\
\hline 7 & + & - & - & ND & + & - & - & + & + & - & - & - & + & + & + \\
\hline 8 & + & - & + & + & + & - & - & + & + & - & + & - & + & + & + \\
\hline 9 & + & - & + & + & + & - & - & + & + & - & + & + & + & + & + \\
\hline 10 & + & - & + & + & + & - & - & + & + & - & + & + & + & + & + \\
\hline 11 & + & - & + & + & + & - & - & + & + & - & + & + & + & + & + \\
\hline
\end{tabular}

Gr B, granzyme B; Pf, perforin; ND, not done.

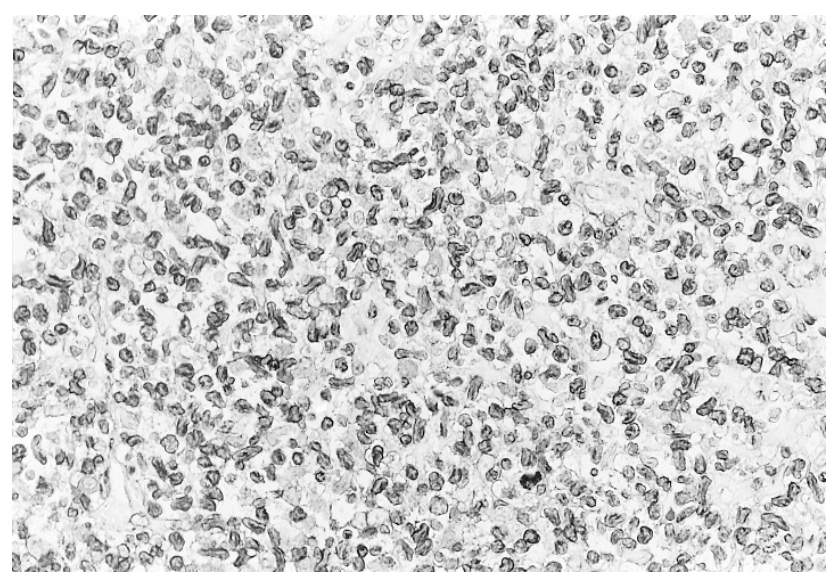

FIGURE 5. CD3 immunostaining reveals positive reactivity mainly in the perinuclear space of the neoplastic cells (Case 1; large cell type) (original magnification, $340 \times$ ).

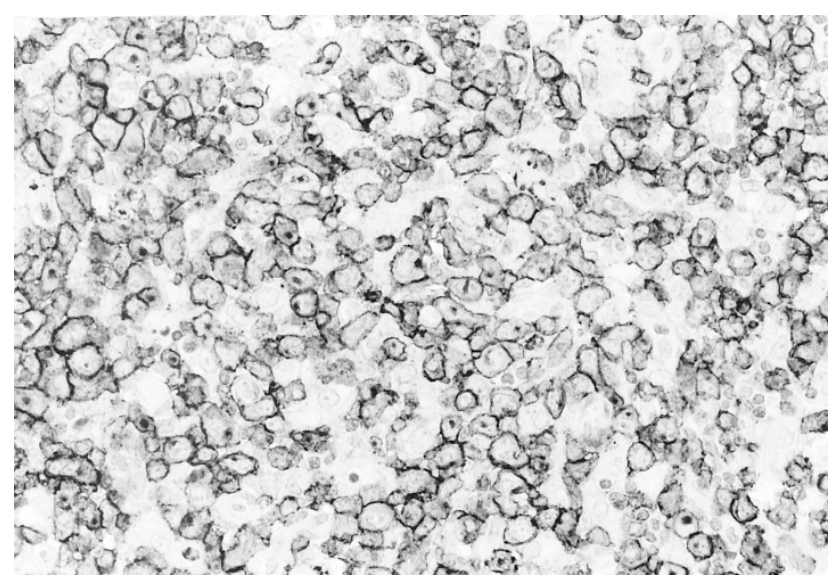

FIGURE 6. CD8 immunostaining reveals positive reactivity in the cytoplasmic membranes of the neoplastic cells (Case 2; large cell type) (original magnification, $680 \times$ ).

(three out of six) of the CD8+ cutaneous PTCLs in our 155 cases expressed the full range of cytotoxic molecules. Two of six expressed only TIA-1 and another case did not express any cytotoxic molecules. All of 11 nodal cytotoxic T-cell lymphomas expressed perforin and $\mathrm{GrB}$, and these are thought to be consistent with activated cytotoxic T-cells. The majority of the cytotoxic T-cell lymphomas

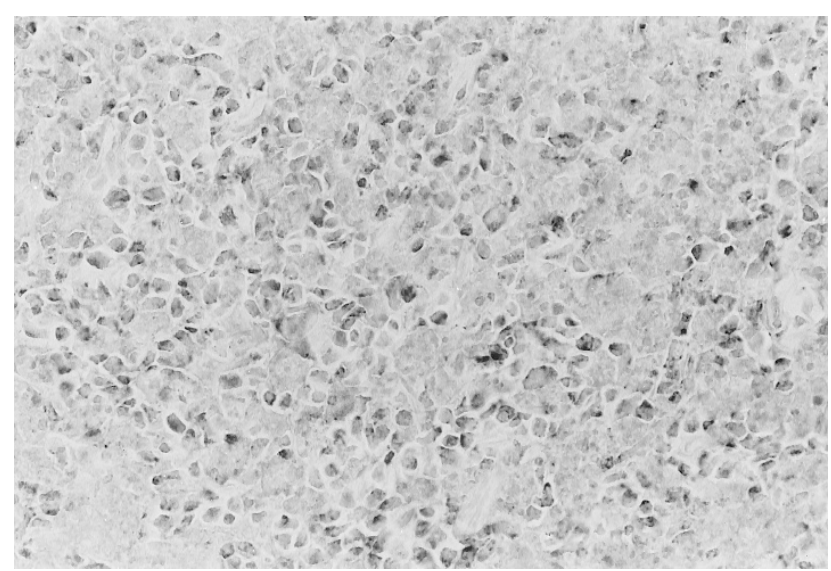

FIGURE 7. Perforin immunostaining reveals granular positive staining in the neoplastic cells using frozen tissue sections (Case 1) (original magnification, $680 \times$ ).

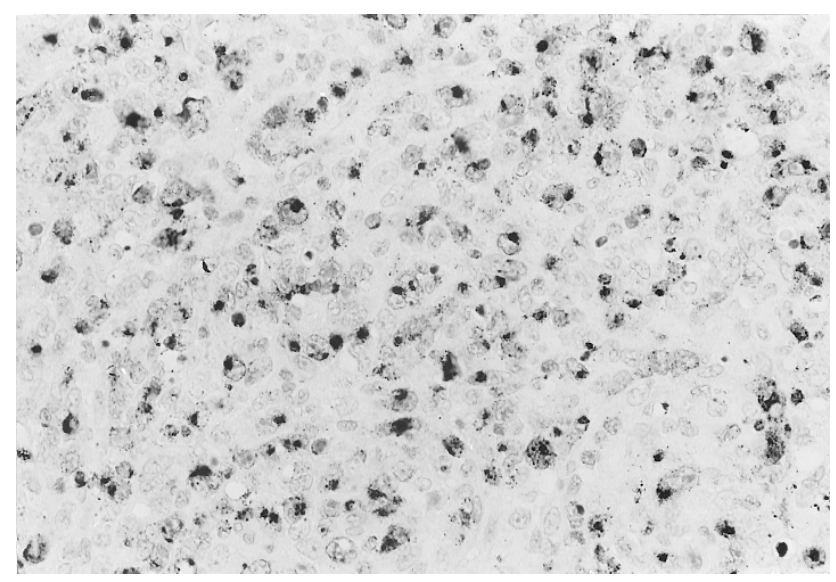

FIGURE 8. Granzyme B immunostaining reveals positive reactivity in the cytoplasm of the neoplastic cells including Golgi areas (Case 2) (original magnification, $680 \times$ ).

with DIC and HPS in the initial disease were accompanied by high expressions of perforin and GrB.

In this study we divided 11 nodal cytotoxic lymphomas into two groups, a large cell type and a medium or mixed cell type. The prognosis of the former group is fulminant and resistant to conventional chemotherapy. Of seven cases of cytotoxic 


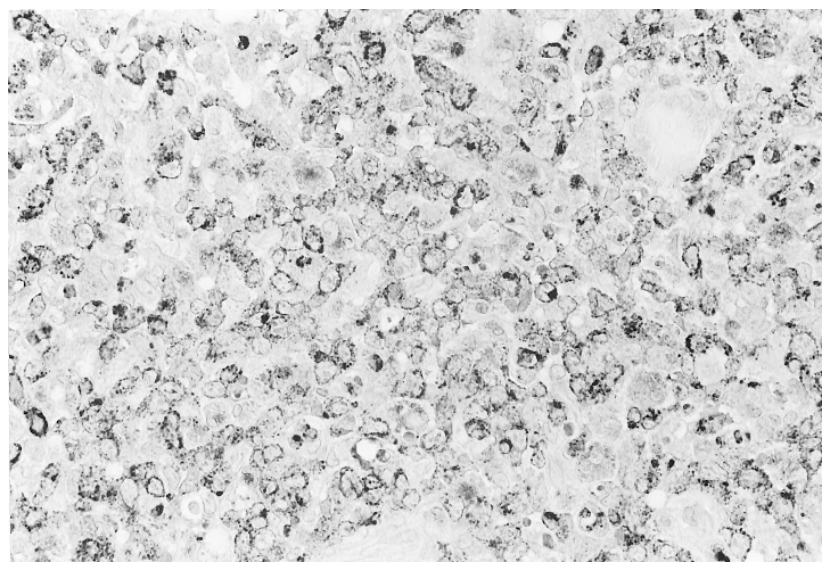

FIGURE 9. TIA-1 immunostaining reveals granular positive reactivity in the cytoplasm of neoplastic cells (Case 2) (original magnification, $680 \times)$.

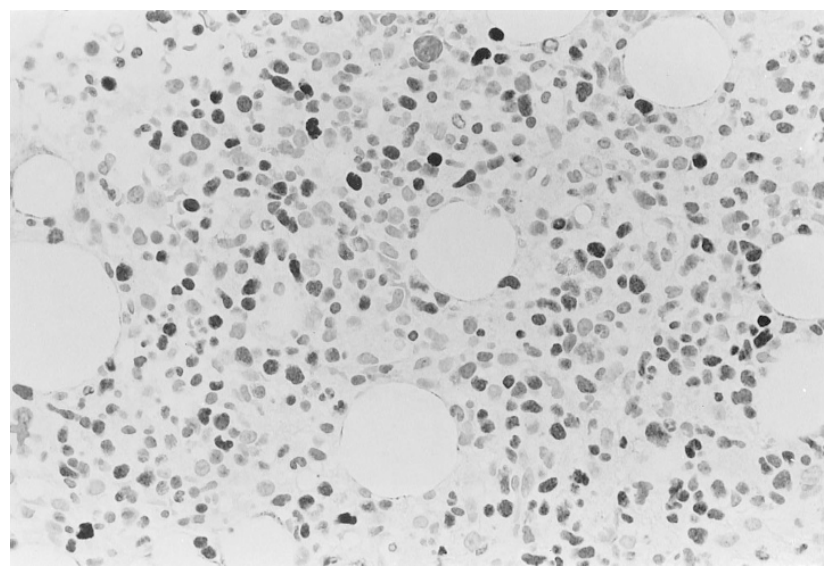

FIGURE 10. EBER-1 in situ hybridization reveals positive nuclear signals in the neoplastic cells in the bone marrow (Case 10) (original magnification, $340 \times$ ).

large T-cell lymphoma examined by Kagami et al., five had a CD4-, CD8+ phenotype and two had a CD4-, CD8- phenotype (39). Most of the seven cases had HPS and thus had a poor prognosis. Our first group resembled their cytotoxic large T-cell lymphoma, but the rate of EBV-positive cases was different. Kagami et al. showed that all of the seven lymphomas that they examined were positive for
EBV and named the lymphomas "EBV-associated cytotoxic large T-cell lymphomas." However, the incidence of EBER-1 in our cases was lower (two of six cases were positive). Kagami et al. also reported two cases of EBV-associated CD8+ cytotoxic large T-cell lymphoma (43). These two cases were quite fulminant and died with rapid progression of DIC. The second group of our nodal cytotoxic T-cell lymphomas was sensitive to conventional chemotherapy in their initial disease. The prognosis of this group was not so poor compared with the first group, but DIC or HPS appeared when their lymphomas had been relapsed or progressed, and the serum levels of IFN- $\gamma$ were increased, (but serum levels of TNF- $\alpha$ did not increase). A previous study of HPS in association with EBV-positive lymphoproliferative disorders has implicated both IFN- $\gamma$ and TNF- $\alpha$ as causative agents (35). On the other hand, macrophage inflammatory protein- $1 \alpha$ (MIP$1 \alpha$ ) and IFN- $\gamma$ (but not TNF- $\alpha$ ) were highly expressed in tissues of patients with HPS caused by EBV-associated T/NK cell lymphomas (44). The second group of our cases resembles two cases of the CD4-, CD8+ phenotype in Kagami's report that were described as "node-based low-grade peripheral T-cell lymphoma." The CD4+, CD8- phenotype lymphoma in the group was TIA-1 positive and GrB negative, whereas the CD4-, CD8+ phenotype was both TIA-1 and GrB positive.

In this report, we described nodal cytotoxic lymphomas that have the CD4-, CD8+ phenotype that express perforin and $\mathrm{GrB}$, which are markers of activated cytotoxic T-cells. These lymphomas were frequently accompanied with DIC or HPS and the prognosis was poor. Most of the cases were resistant to conventional chemotherapy and high dose chemotherapy with stem cell rescue was needed. But it is difficult to continue high dose chemotherapy because of the damage to organs, such as liver and kidney, by cytotoxic proteins and cytokines. It was not clear whether nodal cytotoxic T-cell lymphoma was associated with EBV in this study. In conclusion, these CD4-, CD8+ nodal cytotoxic T-cell lymphomas originated from activated cyto-

TABLE 4. Comparison of Cytotoxic Molecule Expression among Cytotoxic Lymphomas

\begin{tabular}{|c|c|c|c|}
\hline Classification & TIA-1 & Perforin & Granzyme B \\
\hline Present cases & $100 \%(11 / 11)$ & $100 \%(11 / 11)$ & $100 \%(11 / 11)$ \\
\hline CD8+ PTCL (33) & ND & $90 \%(9 / 10)$ & $90 \%(9 / 10)$ \\
\hline EBV-associated cytotoxic large T-cell lymphoma (39) & $100 \%(8 / 8)$ & ND & $100 \%(8 / 8)$ \\
\hline NK-cell lymphoma (40) & $100 \%(14 / 14)$ & $100 \%(14 / 14)$ & $100 \%(13 / 13)$ \\
\hline NK-cell lymphoma (33) & ND & $100 \%(10 / 10)$ & $100 \%(10 / 10)$ \\
\hline Non-hepatosplenic $\gamma \delta$ T-cell lymphoma (40) & $100 \%(5 / 5)$ & $100 \%(5 / 5)$ & $100 \%(5 / 5)$ \\
\hline Subcutaneous panniculitic T-cell lymphoma (42) & $100 \%(16 / 16)$ & $100 \%(16 / 16)$ & ND \\
\hline Hepatosplenic $\gamma \delta$ T-cell lymphoma (40) & $100 \%(10 / 10)$ & $0 \%(0 / 8)$ & $0 \%(0 / 10)$ \\
\hline ALCL (33) & ND & $61 \%(11 / 18)$ & $56 \%(10 / 18)$ \\
\hline ALCL (39) & $85 \%(29 / 34)$ & ND & $54 \%(19 / 35)$ \\
\hline Lennert's lymphoma (41) & $70 \%(7 / 10)$ & ND & $40 \%(4 / 10)$ \\
\hline
\end{tabular}

ND, not done. 
toxic T-cells and can be histologically and clinically distinguished from other peripheral T-cell lymphomas.

\section{REFERENCES}

1. Anderson P, Nagler-Anderson C, O'Brien C, Levine $\mathrm{H}$, Watkins S, Slayter HS, et al. A monoclonal antibody reactive with a $15-\mathrm{kDa}$ cytoplasmic granule associated protein defines a subpopulations of CD8+ T lymphocytes. J Immunol 1990;144:574-82.

2. Garcia-Sanz JA, MacDonald HR, Jenne DE, Tschopp J, Nabholz M. Cell specificity of granzyme gene expression. J Immunol 1990;145:3111-8.

3. Lichtenheld MG, Olsen KJ, Lu P, Lowrey DM, Hameed A, Hengartner H, Podack ER. Structure and function of human perforin. Nature 1988;335:448-51.

4. Liu CC, Walsh CM, Young JDE. Perforin: structure and function. Immunol Today 1995;16:195-201.

5. de Bruin PC, Kummer JA, van der Valk P, van Heerde P, Kluin PM, Willemze R, et al. Granzyme B-expressing peripheral T-cell lymphomas: neoplastic equivalents of activated T cells with preference for mucosa-associated lymphoid tissue localization. Blood 1994;84:3785-91.

6. Felgar RE, Macon WR, Kinney MC, Roberts S, Pasha T, Salhany KE. TIA-1 expression in lymphoid neoplasms. Identification of subsets with cytotoxic $\mathrm{T}$ lymphocyte or natural killer cell differentiation. Am J Pathol 1997;150:1893-900.

7. Chan WC, Link S, Mawle A, Check I, Brynes RK, Winton EF. Heterogeneity of large granular lymphocyte proliferations: delineation of two major subtypes. Blood 1986;68:1142-53.

8. Macon WR, Williams ME, Greer JP, Hammer RD, Glick AD, Collins RD, et al. Natural killer-like T-cell lymphomas: aggressive lymphomas of T-large granular lymphocytes. Blood 1986;87:1474-83.

9. Suzumiya J, Takeshita M, Kimura N, Kikuchi M, Uchida T, Hisano S, et al. Expression of adult and fetal natural killer cell markers in sinonasal lymphomas. Blood 1994;83:2255-60.

10. Emile JF, Boulland ML, Haioun C, Kanavaros P, Petrella T, Delfau-Larue MH, et al. CD5-/CD56+ T-cell receptor silent peripheral T-cell lymphomas are natural killer cell lymphomas. Blood 1996;87:1466-73.

11. Jaffe ES, Chan JKC, Su IJ, Frizzera G, Mori S, Feller AC, et al. Report of the workshop on nasal and related extranodal angiocentric T/natural killer cell lymphomas. Am J Surg Pathol 1996;20:103-11.

12. Mori N, Yatabe Y, Oka K, Kinoshita T, Kobayashi T, Ono T, et al. Expression of perforin in nasal lymphoma. Am J Pathol 1996;149:699-705.

13. Chan JKC, Sin VC, Wong KF, Ng CS, Tsang WY, Chan CH, et al. Nonnasal lymphoma expressing the natural killer cell marker CD56: a clinicopathologic study of 49 cases of an uncommon aggressive neoplasm. Blood 1997;89:4501-13.

14. Cooke CB, Krenacs L, Stetler-Stevenson M, Greiner TC, Raffeld M, Kingma DW, et al. Hepatosplenic T-cell lymphoma: a distinct clinicopathologic entity of cytotoxic T-cell origin. Blood 1996;88:4265-74.

15. Salhany KE, Feldman M, Kahn MJ, Perrit D, Schretzenmair $\mathrm{RD}$, Wilson DM, et al. Hepatosplenic gamma delta T-cell lymphoma: ultrastructural, immunophenotypic, and functional evidence for cytotoxic T lymphocyte differentiation. Hum Pathol 1997;28:674-85.

16. Kumar S, Krenacs L, Raffeld M, Jaffe ES. Subcutaneous panniculitis-like T-cell lymphoma is a tumor of cytotoxic T lymphocytes [abstract]. Mod Pathol 1997;10:129A.

17. Salhany KE, Macon WR, Choi JK, Elenitsas R, Lessin SR, Felgar RE, et al. Subcutaneous panniculitis-like T-cell lymphoma: clinicopathologic, immunophenotypic, and geno- type analysis of alpha/beta and gamma/delta subtypes. Am J Surg Pathol 1998;22:881-93.

18. Foss HD, Anagnostopoulos I, Araujo I, Assaf I, Demel G, Kummer JA, et al. Anaplastic large cell lymphomas of T-cell and null-cell phenotype express cytotoxic molecules. Blood 1996;88:4005-11.

19. Krenacs L, Wellmann A, Sorbara L, Himmelmann AW, Bagdi E, Jaffe ES, et al. Cytotoxic cell antigen expression in anaplastic large cell lymphomas of T- and null-cell type and Hodgkin's disease: evidence for distinct cellular origin. Blood 1997;89:980-9.

20. Kagi D, Ledermann B, Burki K, Zinkernagel RM, Hengartner H. Lymphocyte-mediated cytotoxicity in vitro and in vivo: mechanisms and significance. Immunol Rev 1995;146:95115.

21. Berke G. The CTCL's kiss of death. Cell 1995;81:9-12.

22. Smyth MJ, Trapani JA. Granzymes: exogenous proteinases that induce target cell apoptosis. Immunol Today 1995;16: 202-6.

23. Stalder T, Hahn S, Erb P. Fas antigen is the major target molecule for CD4+ T-cell-mediated cytotoxicity. J Immunol 1994;152:1127-33.

24. Tian Q, Streuli M, Saito H, Schlossman SF, Anderson P. A polyadenylate binding protein localized to the granules of cytolytic lymphocytes induces DNA fragmentation in target cells. Cell 1991;67:629-39.

25. Darmon AJ, Nicholson DW, Bleackley RC. Activation of the apoptotic protease CPP32 by cytotoxic T-cell-derived granzyme B. Nature 1995;377:446-8.

26. Froelich CJ, Dixit VN, Yang X. Lymphocyte granule-mediated apoptosis: matters of viral mimicry and deadly proteases. Immunol Today 1998;19:30-6.

27. Lanier LL, Spits H, Phillips JH. The developmental relationship between NK cells and T cells. Immunol Today 1992;13: 392-4.

28. Griffiths GM, Mueller C. Expression of perforin and granzymes in vivo: potential diagnostic markers for activated cytotoxic cells. Immunol Today 1991;12:412-9.

29. Salcedo TW, Azzoni L, Wolf SF, Perussia B. Modulation of perforin and granzyme messenger RNA expression in human natural killer cells. J Immunol 1993;151:2511-20.

30. Koizumi H, Liu CC, Zheng LM, Joag SV, Bayne NK, Holoshitz $\mathrm{J}$, et al. Expression of perforin and serine-esterases by human $\gamma / \delta$ T cells. J Exp Med 1991;173:499-502.

31. Medley QG, Kedersha N, O’Brien S, Tian Q, Schlossman SF, Streuli M, et al. Characterization of GMP-17, a granule membrane protein that moves to the plasma membrane of natural killer cells following target cell recognition. Proc Natl Acad Sci USA 1996;93:685-9.

32. Hahn S, Gehri R, Erb P. Mechanism and biological significance of CD4-mediated cytotoxicity. Immunol Rev 1995;146: 57-79.

33. Yamashita Y, Yatabe Y, Tsuzuki T, Nakayama A, Hasegawa Y, Kojima H, et al. Perforin and granzyme expression in cytotoxic T-cell lymphomas. Mod Pathol 1998;11:313-23.

34. Chang JKC, Chen Y, Shibata D, Weiss L. Description of an in situ Epstein-Barr virus RNA in paraffin-embedded tissues, with a survey of normal and neoplastic tissues. Diagn Mol Pathol 1990;1:246-55.

35. Lay J-D, Tsao C-J, Chen J-Y, Kaden ME, Su IJ. Upregulation of tumor necrosis factor- $\alpha$ gene by Epstein-Barr virus and activation of macrophages in Epstein-Barr virus-infected $\mathrm{T}$ cells in the pathogenesis of hemophagocytic syndrome. J Clin Invest 1997;100:1969-79.

36. Montalban C, Obeso G, Gallego A, Castrillo JM, Bellas C, Rivas C. Peripheral T-cell lymphoma: a clinicopathological study of 41 cases and evaluation of the prognostic significance of the updated Kiel classification. Histopathology 1993;22:303-10. 
37. Chan JKC, Ng CS, Lau WH, Lo STH. Most nasal/nasopharyngeal lymphomas are peripheral T-cell neoplasms. Am J Surg Pathol 1987;11:418-29.

38. Phillips JS, Hori T, Nagler A, Bhat N, Spitz H, Lanier LL. Ontogeny of human natural killer (NK) cells: fetal NK cells mediate cytolytic function and express cytoplasmic CD3 proteins. J Exp Med 1992;175:1055-66.

39. Kagami Y, Suzuki R, Taji H, Yatabe Y, Takeuchi T, Maeda S, et al. Nodal cytotoxic lymphoma spectrum. A clinicopathologic study of 66 patients. Am J Surg Pathol 1999;23:1184200.

40. Boulland M-L, Kanavaros P, Wechsler J, Casiraghi O, Gaulard P. Cytotoxic protein expression in natural killer cell lymphomas and in $\alpha \beta$ and $\gamma \delta$ peripheral T-cell lymphomas. J Pathol 1997;183:432-9.
41. Yamashita Y, Nakamura S, Kagami Y, Hasegawa Y, Kojima H, Nagasawa T, et al. Lennert's lymphoma. A variant of cytotoxic T-cell lymphoma? Am J Surg Pathol 2000;24:1627-33.

42. Kumar S, Krenacs L, Medeiros J, Elenitoba-Johnson KSJ, Griner TC, Sorbara L, et al. Subcutaneous panniculitic T-cell lymphoma is a tumor of cytotoxic T lymphocytes. Hum Pathol 1998;29:397-403.

43. Kagami Y, Sobue R, Ito N, Yatabe Y, Taji H, Suzuki R, et al. Cytotoxic large $\mathrm{T}$-cell lymphoma with fulminant clinical course, CD8+ and CD56- phenotype, and its relation to Epstein-Barr virus: a report of two cases. Int J Hematol 1999;70:105-111.

44. Teruya-Feldstein J, Setsuda J, Yao Xu, Kingma DW, Straus S, Tosato G, et al. MIP-1 $\alpha$ expression in tissues from patients with hemophagocytic syndrome. Lab Invest 1999;79:1583-1590.

\section{Book Review}

\section{Lewandrowski K: Clinical Chemistry: Labora- tory Management and Clinical Correla- tions, 976 pp, Baltimore, Lippincott Wil- liams \& Wilkins, 2002 (\$125.00).}

This text is an excellent resource for clinical laboratory personnel, covering both the technical and management aspects of lab operations. Experienced administrators and scientists have collaborated to produce a text that is both comprehensive and detailed. The book is unique in that it addresses several practical issues laboratorians face on a daily basis, including regulatory issues, economic pressures, management challenges, and trends in automation. The text is comprised of three sections, the first of which addresses the full range of management issues, including human resources, budget control, specimen transport networks, and information systems. The second section contains chapters covering laboratory techniques, contemporary instrumentation, and clinical chemistry methodologies. The last section, titled "Analysis and Clinical Correlations," deals with laboratory tests as the basis for the pathophysiological evaluation of disease. This section includes chapters on important analytes including plasma proteins, electrolytes, and lipids. The chapters on cerebrospinal fluid evaluation, toxicology, and coagulation are particularly useful. I highly recommend this book as a unique and comprehensive reference for clinical laboratorians and for those in clinical pathology training.

\author{
Brian E. Moore \\ Roger Williams Medical Center \\ Department of Stem Cell Research \\ Providence, Rhode Island
}

